\title{
Application of Improved AHP Method in Insurance Enterprise Promotion
}

\author{
Ru Duan ${ }^{1}$, Ning Liu ${ }^{2}$ \\ ${ }^{1}$ Department of insurance, HeBei Finance University, Baoding, 071000, China \\ ${ }^{2}$ College of Finance \& Economics ,Hebei Normal University of Science \& Technology, Qinhuangdao, \\ 066000, China
}

Keywords: Improved AHP; Indicator system ; Ability to work

\begin{abstract}
Core staff of insurance enterprise has a special status in the insurance enterprise, and it's significant for insurance enterprises' long-term development to evaluate and select them. In this paper, the improved analytic hierarchy process evaluation model is used to build the work capacity evaluation model, optimize evaluation index weights, determine the evaluation matrix and finally get the staff's comprehensive performance. The ability to work through this model to evaluate the merits of the staff, will optimize the insurance company's human resources, the potential to motivate employees to improve employee motivation, increase efficiency and thus enhance the competitiveness of insurance enterprises, improve economic efficiency of insurance enterprises.
\end{abstract}

\section{Introduction}

Analytic hierarchy process (AHP) is a practical scheme or multi-objective decision-making method, which is proposed by professor Satty in the $80 \mathrm{~s}$. Its obvious deficiencies is prone to arbitrariness, subjectivity in the matrix structure, and its judgment matrix do not have transitivity. Since 1982 the method was introduced to our country, with its combination of qualitative and quantitative characteristics of the decision-making to deal with a variety of factors, as well as its advantages of simple and flexible, rapidly in the fields of social economy, has been widely attention and application. But its obvious deficiencies are prone to arbitrariness, subjectivity when constructing the matrix, and it does not have to pass at the time of the judgment matrix, the need for consistency test, which we introduce an improved AHP to determine the weights [1-3].

Core employees of the insurance sector has a special position in the enterprise. They usually have the expertise to master the core business, to control the development of key resources and enterprises have a profound impact. If the enterprise can make the right reasonable evaluation for core staff's job performance and as a basis for their promotion of development, the allocation of human resources will be optimized, the motivate potential to improve economic efficiency of enterprises will be stimulated. In the whole selection process, the subjective human factors conducted the results. Employee performance appraisal should follow the following principles [4]:Objective and fair, democratic and open manner principle, focusing on work performance principle and hierarchical set of performance evaluation dimensions principles.

Over the years, the insurance sector often uses the democratic form of evaluation in the selection of cadres, which is lack of reasonable evaluation and scientific evaluation methods, and has strong subjective human factors. Moreover, it is difficult to ensure the fair, which will damage the enthusiasm of core staff and contrary to the overall objective of the electricity sector. Thus we advocate the use of improved AHP to improve scientific impartiality of staff selection[5,6].

\section{Establish indicator system}

The fundamental purpose of employee evaluation is through the proper evaluation of the employee's job performance, work ethics, work ability, work attitude, work performance and job potential, etc., combined with the deployment of personnel, promotion, compensation, and education and training and other management tools to improve each employee the ability, quality and morale, to achieve business goals. Examination content is divided into three areas: job performance, work attitude and ability to work $[7,8]$. 
Work ability is the determination of the conditions for staff promotion. Different objects have different appraisal evaluation content. Some of the functions of management can be their ability to work as a comprehensive assessment of the most important content. Especially for enterprise core staff, the ability is a key element of performance. We designed the 26 decomposition items about core staff's work ability through the data access, combined with practical work experience and the use of expert evaluation method. The work ability of core staff evaluation index system is shown as Table 1.

Table 1 . The work ability of core staff evaluation index system

\begin{tabular}{|c|c|}
\hline Specific capabilities & Indicators \\
\hline Knowledge skills & $\begin{array}{l}\text { Understanding of the business, } \\
\text { working methods, and procedures } \\
\text { Familiarity with the laws and } \\
\text { regulations on insurance } \\
\text { The ability to use computers to } \\
\text { manage business } \\
\text { Management knowledge } \\
\text { Ability to read preference in English }\end{array}$ \\
\hline Decision-making capacity & $\begin{array}{l}\text { Accuracy of decision-making } \\
\text { Speed of decision-making } \\
\text { Overall planning capacity }\end{array}$ \\
\hline Coordination skills & $\begin{array}{l}\text { Ability to deal with conflict } \\
\text { Work organization } \\
\text { Ability to launch advocacy } \\
\text { Ability of communication and } \\
\text { influencing } \\
\text { Spirit of cooperation }\end{array}$ \\
\hline Innovation capacity & $\begin{array}{c}\text { Ability to foresee } \\
\text { Accept advanced ideas and practical } \\
\text { ability } \\
\text { Try to explore the capabilities and } \\
\text { anti- frustration }\end{array}$ \\
\hline Comprehension & $\begin{array}{c}\text { Superior ability to understand the } \\
\text { intent and command } \\
\text { Inductive analysis capability } \\
\text { Reaction speed } \\
\text { Application capabilities } \\
\text { Ability to deal with global and local } \\
\text { relationships } \\
\end{array}$ \\
\hline Work experience & $\begin{array}{l}\text { According to experience the ability } \\
\text { to handle emergencies } \\
\text { Sum up experience, the ability to } \\
\text { work to improve business } \\
\text { Security awareness and } \\
\text { accountability }\end{array}$ \\
\hline Presentation skills & $\begin{array}{c}\text { Verbal ability } \\
\text { Insurance document writing ability }\end{array}$ \\
\hline
\end{tabular}

\section{Improved AHP model applied in core staff evaluation}

Analytic hierarchy process (AHP) is a combination of qualitative and quantitative, systematic, hierarchical analysis problems method. It makes the layers hierarchical through the people's thought 
processes, compare relevant factors and intervening layer by layer test to compare the results are reasonable, so as to analyze the decision-making to provide a more convincing quantitative basis.

The concrete steps of improved is shown as follow:

(1) Set samples for $n, N=\{1,2, \cdots, n\}$, targets involved in staff selection for $m$, $M=\{1,2, \cdots, m\} . \quad X_{n \times m}=x_{i j}$ is $j$ th index value of $i$ th sample. Set $x_{j}$ is the sample mean value of $j$ th index, $X_{j}=\frac{1}{n} \sum_{j=1}^{n} X_{i j}(j \in M) . Y_{m \times c}$ is $m \times c$-order standard eigenvalue matrix.

(2) Use three scales method to build comparison matrix.

Set $a_{i j}= \begin{cases}1 & \text { indicator } i \text { is more important than indicator } j \\ 0 & \text { indicator } i \text { and is indicator } j \text { are equally important } \\ -1 & \text { indicator } i \text { is less important than indicator } j\end{cases}$

Thus, the three scales comparison matrix $A$ is $\left(a_{i j}\right)_{m \times m},(i, j \in M)$.

(3) Calculate the importance degree ordering index.

The importance degree ordering index of indicator $i$ is $r_{i}=\sum_{j=1}^{n} a_{i j}(i \in M)$. And the Minimum essential degree ordering index is $r_{\min }=\stackrel{\min }{i} \in M^{r_{i}}$.

(4) Build indirect judgment matrix.

The elements $b_{i j}$ in the indirect judgment matrix $B$ is set as $\mathrm{Eq}(2)$.

$$
b_{i j}= \begin{cases}\frac{r_{i}-r_{j}}{r_{\min }+1} & r_{i} \geq r_{j} \\ {\left[\frac{r_{i}-r_{j}}{r_{\min }+1}\right]^{-1}} & r_{i}<r_{j}\end{cases}
$$

(5) Calculate the antisymmetric matrix.

The antisymmetric matrix of the indirect judgment matrix $B$ is set as:

$C=\left(c_{i j}\right)_{n \times m}$

where $c_{i j}$ equals to $\lg b_{i j}$.

(6) Calculate the optimal transfer matrix.

The optimal transfer matrix of the antisymmetric matrix $C$ is set as $D=\left(d_{i j}\right)_{m \times m}$, where elements $d_{i j}$ is set as $\operatorname{Eq}(4)$.

$$
d_{i j}=\frac{1}{m} \sum_{k=1}^{m}\left(c_{i k}-c_{j k}\right)
$$

(7) Build quasi optimal consistent matrix.

The quasi optimal consistent matrix of indirect judgment matrix $B$ is set as:

$$
B^{*}=\left(b_{i j}^{*}\right)_{m \times m}, \text { where } b_{i j}^{*}=10^{d_{i j}} .
$$

(8) Weight normalization.

$$
w_{j}=\left(\sum_{i=1}^{m} b_{i j}^{*}\right)^{-1},(j \in M)
$$


The weights $w_{i j}$ of program layer $C_{i}$ in terms of guidelines layer $B_{i}$ are calculated respectively. Then, the weights $w_{i}$ of program layer $C_{i}$ in terms of target layer $A$ are calculated as $\operatorname{Eq}(7)$.

$$
w_{j}=\sum_{j=1}^{m} w_{i} \times w_{i j},(j=1,2, \cdots, 13)
$$

(9) During the inspection process, the evaluation experts respectively scores for a certain candidate's 13 working ability. As for every indicator of the working ability, there are four grades, including "excellent"(in terms of $e$ ), "competent"(in terms of $c$ ), "basically competent"(in terms of $b$ ) and "incompetent"(in terms of $I$ ). Thus, the work ability evaluation matrix $R$ is set as $\mathrm{Eq}(8)$.

$$
R=\left[\begin{array}{cccc}
d_{1} / m & e_{1} / m & f_{1} / m & g_{1} / m \\
d_{2} / m & e_{2} / m & f_{2} / m & g_{2} / m \\
d_{3} / m & e_{3} / m & f_{3} / m & g_{3} / m \\
\vdots & \vdots & \vdots & \vdots \\
d_{26} / m & e_{26} / m & f_{26} / m & g_{26} / m
\end{array}\right]
$$

(10) Fuzzy comprehensive evaluation result vector is set as $\mathrm{Eq}(9)$.

$$
B=M \times R \text {. }
$$

Where $B$ is the working ability comprehensive evaluation value of core staff, $M$ is the final weights vector of program layer in terms of target layer in the working ability hierarchical structure model, $R$ means the working ability evaluation matrix.

The principle of maximum membership causes information loss easily, thus using the weighted average principle, which is shown in $\mathrm{Eq}(10)$.

$$
A=\frac{\sum_{j=1}^{m} b_{j}^{k} \times j}{\sum_{j=1}^{m} b_{j}^{k}} \quad(k=2)
$$

Where $A$ is the final evaluation score of the core staff. According to the score of the comprehensive performance of core staff, enterprise can require a scientific and rational conclusion about the working ability of the core staff, which can provide the basis for official selection in a fair distribution of bonus and welfare, in order to encourage staff to work more effectively.

\section{Conclusion}

The improved AHP is used into the reward ascension of core staff in insurance enterprise, then it can greatly increase the objectivity and fairness of the evaluation results, reduce the influence of subjective human factors, and improve the management level of the organization. The judgment matrix of this approach satisfies consistent completely, so we needn't check for consistency. Furthermore, using the weighted average principle in fuzzy comprehensive evaluation is not easy to cause the loss of information. As the basis of core employee selection promotion, fair and reasonable evaluation result can optimize the distribution of human resources, motivate staff potential, boost the enthusiasm of the employees and increase efficiency, so as to improve the competitive ability of insurance enterprises, as well as enterprise economic benefits. 


\section{References}

[1] F. Lolli, A. Ishizaka, R. Gamberini. New AHP-based approaches for multi-criteria inventory classification. International Journal of Production Economics. 156, pp.62-74, 2014.

[2] Jafar Rezaei, Patrick B.M. Fahim, Lori Tavasszy. Supplier selection in the airline retail industry using a funnel methodology: Conjunctive screening method and fuzzy AHP. Expert Systems with Applications. 41, pp.8165-8179, 2014.

[3] Shin-ichi Ohnishi, Takahiro Yamanoi. On Fuzzy Priority Weights of AHP for Double Inner Dependence Structure. Procedia Computer Science. 35, pp.1003-1012, 2014.

[4] Jiř́i Franek, Aleš Kresta. Judgment Scales and Consistency Measure in AHP. Procedia Economics and Finance. 12, pp.164-173, 2014.

[5] Xiaobing Yu, Shunsheng Guo, Jun Guo, Xiaorong Huang. Rank B2C e-commerce websites in e-alliance based on AHP and fuzzy TOPSIS. Expert Systems with Applications. 38, pp. 3550-3557, 2011.

[6] Reza Eslamipoor, Abbas Sepehriar. Firm relocation as a potential solution for environment improvement using a SWOT-AHP hybrid method. Process Safety and Environmental Protection. 92, pp. 269-276, 2014.

[7] Orlando Durán. Computer-aided maintenance management systems selection based on a fuzzy AHP approach. Advances in Engineering Software. 42, pp. 821-829, 2011.

[8] Jose Antonio Gomez-Ruiz, Marcelo Karanik, José Ignacio Peláez. Estimation of missing judgments in AHP pairwise matrices using a neural network-based model. Applied Mathematics and Computation. 216, pp. 2959-2975, 2010. 